\title{
Use of Natural Sorbent for Stormwater Treatment
}

\author{
Marina Valentukevičiene $\dot{1}^{*}$, Maryam Ebrahimian Najafabadi ${ }^{2}$ \\ ${ }^{I}$ Department of Water Management, Vilnius Gediminas Technical University, Vilnius, Lithuania \\ ${ }^{2}$ Faculty of Natural Resources and Environment, Malayer University, Malayer, Iran
}

Received 04 February 2020; accepted 31 March 2020

\begin{abstract}
Stormwater runoff is an important avenue for pollutant transport from impermeable surfaces to surface waters. Consequently, stormwater pollutions require additional treatment processes to achieve water quality goals. Natural sorbents have been demanded and studied for using in water treatment because of their low cost and safety. In this study the use of Acorus Calamus, row Hemp, and procedure Hemp in stormwater treatment was investigated. Results of study in all sorbents with different concentrations and dosage indicated high efficiency to reduce $\mathrm{pH}$. The use of Acorus Calamus for Turbidity, Phosphorus, conductivity and colour resulted increasing amount in different Dosage. In another experiments, using row Hemp, procedure Hemp and Linseed as natural sorbents indicated high efficiency to reduce turbidity of stormwater. Also it is obtained that procedure Hemp has high efficiency to reduce conductivity of stormwater.
\end{abstract}

Keywords: Hemp, stormwater, natural sorbent, water quality.

\section{Introduction}

Urban rainwater runoff contains many pollutants generated by human activities and natural processes stormwater runoff can contain pollutants from fertilizers and pet and yard waste. Surface water and rain water are often the major sources of water availability in a community (Ernest et al., 2017). During periods of heavy rainfall some wastewater systems are designed to occasionally overflow and discharge excess untreated sewage directly to nearby streams (Pearson et al., 2018), rivers or other water bodies that it has become a non-point source pollution problem commonly existing in various countries across the world (Fu, 2015; Mangale et al., 2012).

The clean water for our need is obtained mostly from river so a proper wastewater treatment is to be needed before being released to the river. Different processes need a different kind of water treatment Through leaching and transport processes, however, excess phosphorus can endanger the quality of surface waters (Mahmood \& Zaki, 2019). Phosphorus inputs to water bodies are under close scrutiny because of the contribution of phosphorus to water eutrophication and algal blooms (Yu et al., 2019), which result in the depletion of dissolved oxygen and high turbidity levels in aquatic ecosystem (Hsieh et al., 2007) High turbidity in water not only will reduce the quality of water itself (Abidin et al., 2013; Choy et al., 2014) but it can give impact to the ecosystem as well (Ernest et al., 2017). It indicates the presence of TSS (Total Suspended Solids) like clay, silt, organic matter which can be harmful for mankind, biologically as well as chemically (Lopez \& Postila, 2018). In fact Turbidity refers to the cloudiness of a solution and its characteristics that are imparted by the suspended solid particles limiting the passing of light through water. The history of the use of sorption process to remove turbidity in water is long (Okuda \& Ali, 2019) series of sorption experiment were conducted to establish the reduction of turbidity (Sahu et al., 2019). Depending on the application, chemical reagents are dosed into the water stream to increase coagulation and formation of flocs and effectiveness of settling before filtration (Javid et al., 2015) Biosorption is an emerging technique for water treatment utilizing abundantly available biomaterials there has been considerable interests in the development of natural sorbent (Iqbal et al., 2019; Kainth, 2015) which are safe for human health and biodegradable (Ata et al., 2012; Iqbal et al., 2019; Kainth, 2015; Shan et al., 2017). The sorbents with high sorption capacity, easy separation from aqueous solution, low cost, and recycling use are promising materials in the future. Sorption is a method that is preferable when compared with separations like membrane separation and coagulation or flocculation processes Mangalea et al. in 2012 evaluate the efficiency of a natural absorbent from Moringa oleifera seeds in treating river water. Various doses of Moringa seed powder viz. 50, 100 and $150 \mathrm{mg} / \mathrm{l}$ were taken and checked for the efficiency dose on raw water. After treatment of seed powder with water samples were analysed for different parameter like $\mathrm{pH}$, Turbidity. All parameters were reduced with increasing dose of 50, 100 and $150 \mathrm{mg} / \mathrm{l}$ seed powder respectively. Śćiban and co-workers in 2009 were experimented ability of

*Corresponding author. E-mail: marina.valentukeviciene@vgtu.lt 
seed extracts of several species of chestnut and acorn to act as a natural coagulants using a synthetic turbid water. Active components were extracted from ground seeds of Horse chestnut and acorns of some species of family Fagaceae: Common oak, Turkey oak, Northern red oak and European chestnut. All investigated extracts had coagulation capabilities and their amounts depended on $\mathrm{pH}$ values and initial turbidities. The seed extracts from European chestnut and common oak acorn were the most efficient expressing the highest coagulation activities, about $80 \%$ and $70 \%$, respectively, in both low and medium investigated water turbidities at the lowest coagulant dose $0.5 \mathrm{ml} / \mathrm{L}$. In other case Baptista et al. in 2015 were used Moringa oleifera seed to obtain a natural coagulant that was able to reduce the colour and turbidity of surface water with initial turbidity of 75 NTU without increasing the organic material in the water treated. The results indicated that saline coagulant had a better performance in the removal of colour $(89.15 \%)$ and turbidity (88.75\%). Ramavandi in 2014 were extracted a bio coagulant from Plantago ovata by using a $\mathrm{FeCl} 3-$ induced crude extract (FCE). The potential of FCE to act as a natural coagulant was tested for clarification using the turbid water of a river. Experimental tests were performed to evaluate the effects of turbidity concentration, coagulant quantity, water $\mathrm{pH}$, and humic acid concentration on the coagulation of water turbidity by FCE. The maximum turbidity removal was occurred at water $\mathrm{pH} 8$. At the optimum dosage of FCE, only $0.8 \mathrm{mg} / \mathrm{L}$ of dissolved organic carbon was released to the treated water. An increase in the humic acid led to the promotion of the water turbidity removal. Results demonstrated that the FCE removed more than $95.6 \%$ of all initial turbidity concentrations. Mahmood and Zaki in 2019, were measured the effectiveness of Artocarpus Heterophyllus seed as natural coagulant. There are two types the natural coagulant from Artocarpus Heterophyllus were considered in this study such as raw and dried seed. The result showed dried Artocarpus Heterophyllus seed $(1 \mathrm{M} \mathrm{NaCl})$ at $20 \mathrm{mg} / \mathrm{L}$ achieved the optimum dosage of coagulant compared to dried Artocarpus Heterophyllus seed (distilled water), raw Artocarpus Heterophyllus seed (distilled water) and raw Artocarpus Heterophyllus seed $(1 \mathrm{M} \mathrm{NaCl})$ in removing turbidity. It reduced up to 50\% turbidity, and $70 \%$ suspended solid after the treatment process. Kamel and co-workers in 2018 conducted a research to compare the effectiveness of natural based coagulant made from Psophocarpus tetragonolobus and chemical coagulant in improving the quality of raw water. Findings from this study showed $P$ tetragonolobus can remove turbidity up to 60 percent with $40 \mathrm{ml}, 1 \%$ solution. Therefore, $P$. tetragonolobus can be considered as a potential resource for natural coagulant. Rak and Islami in 2012 used Cassia alata leaves to test coagulant rate and dose. The turbidity and other physico-chemicals of surface water sample were measured before and after the jar-test by using portable instruments. The results have shown that Cassia alata leaves can remove turbidity up to $93.33 \%$ at the optimal dosage of $1.0 \mathrm{~mL} / \mathrm{L}$. In this study, we focused our attention on evaluation of Acorus Calamus, Row Hemp, Linseed and procedure Hemp efficiency as biosorbent to decrease Phosphorus, $\mathrm{pH}$, Conductivity, colour and Turbidity in the stormwater. The main aim of this study is evaluation of sorption characterization for these Natural sorbents. This bio-sorbents were obtained from Acorus Calamus, Linseed, procedure Hemp and row Hemp which are abundantly available in Lithuania, as well as in many other countries worldwide like Iran.

\section{Material and methods}

\section{Stormwater}

Samples were collected from VGTU university parking plots located in Vilnius, Lithuania from September 20 till December 14. Table 1 shows the main characteristic of stormwater and snow melted water. According to the results shown in Table 1, Phosphorous, Turbidity and Conductivity of stormwater are in higher level than standards.

Table 1. Characteristics of used stormwater (Vilnius, Lithuania)

\begin{tabular}{|c|c|c|c|c|}
\hline Parameters & Units & $\min$ & $\max$ & Standard \\
\hline Phosphorus & $\mathrm{mg} / \mathrm{l}$ & 1.8 & 9.8 & $1 \mathrm{mg} / 1$ \\
$\mathrm{pH}$ & - & 7.2 & 7.84 & $6.5-8.5$ \\
Conductivity & $\mu \mathrm{S} / \mathrm{cm}$ & 107 & 547 & $<500$ \\
Color & $\mathrm{pt} \mathrm{scale} \mathrm{mg} / \mathrm{l}$ & 1.12 & 5.3 & 5 \\
Turbidity & $\mathrm{mg} / \mathrm{l}$ & 12.7 & 723 & 20 \\
\hline
\end{tabular}

\section{Preparation of used sorbents}

To obtain Acorus Calamus powder as an sorbent, the Acorus Calamus were previously Cleaned, washed with tap water, dried in $120^{\circ} \mathrm{C}$ for one day, ground and then finally sieved by an impact laboratory test sieve with an aperture of $300 \mathrm{~mm}$ to obtain a solid powder with a diameter less of $0.3 \mathrm{~mm}$ (Adesina et al., 2019; Jonesn \& Bridgeman, 2019; Zaidi, 2019). The employed Acorus Calamus was composed of six units, each containing $0.5 \mathrm{~L}$ of stormwater and different amount of fine powder to achieve different concentrations $(2,4,6,8,10 \mathrm{mg} / \mathrm{l})$. The first step of Jar test consisted of stirring the stock solution at 120 rotations per minute (rpm) for roughly 30 minutes. After 30 minutes, the solution was filtered through a Whatman paper (0.45 micron) (Shan et al., 2017; Zaidi, 2019) to obtain filtrated water. 
Finally the pH, Turbidity, Phosphorus, conductivity and colour of filtered sorbent was measured. All the steps of jar test filtration water are shown in Figure 1.

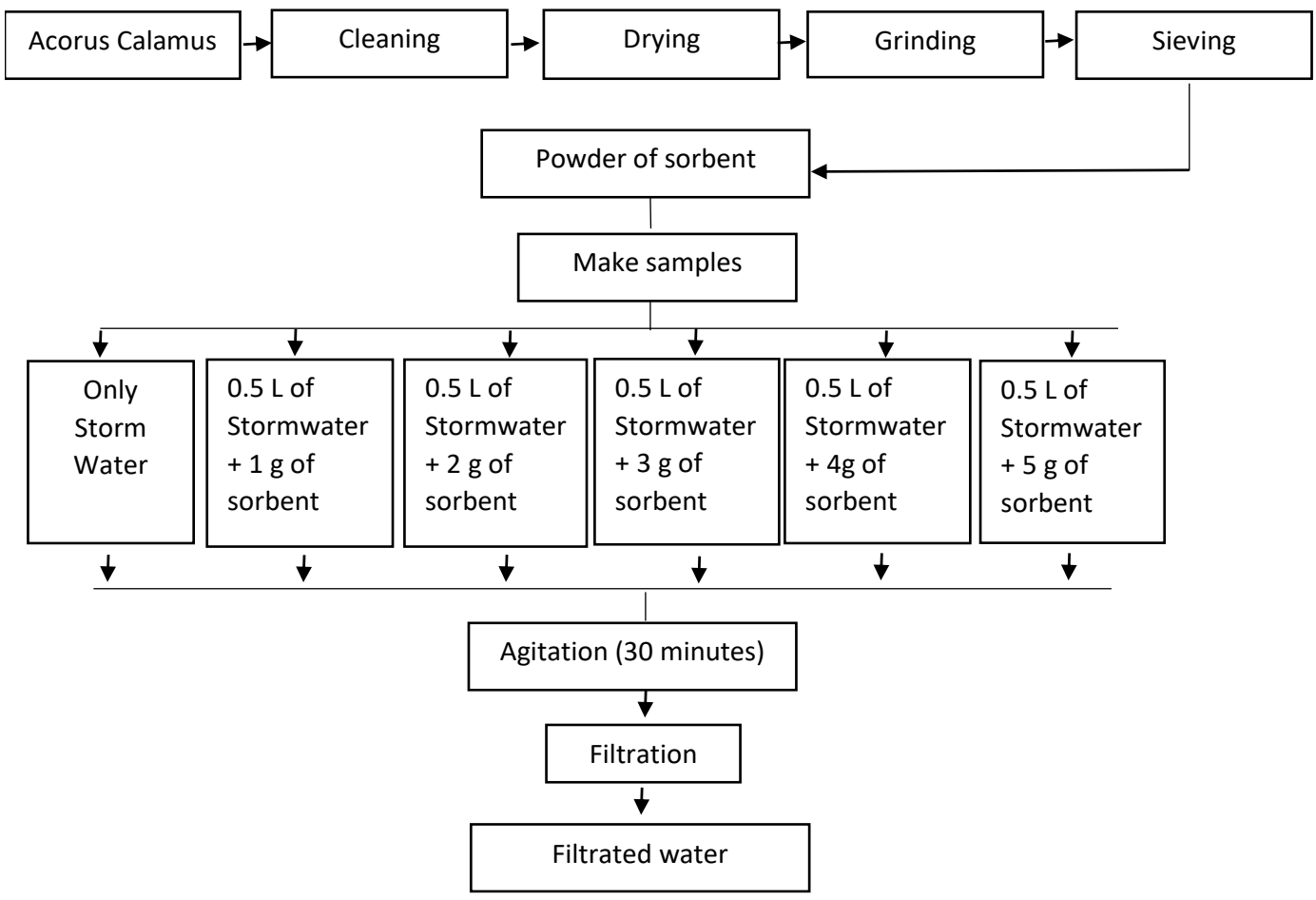

Figure 1. Jar test steps of A. Calamus to obtain filtrated water

In the next experimental research the prepared Row hemp was filled into the filter column and washed to clean. Furthermore $0.5 \mathrm{~L}$ of stormwater was added to the filter column $(40 \mathrm{~cm}$ height and $5 \mathrm{~cm}$ Diameter) for 30 minutes settling to accomplish treated water. After 30 minutes, the solvent was filtered through a Whatman paper ( 0.45 micron) to obtain samples (Zaidi, 2019). This research repeated in different rainy days. Finally PH, Turbidity, Phosphorus, conductivity and colour of filtered sorbent was measured to obtain efficiency of Row Hemp as a sorbent. All steps of the column test are shown in Figure 2.

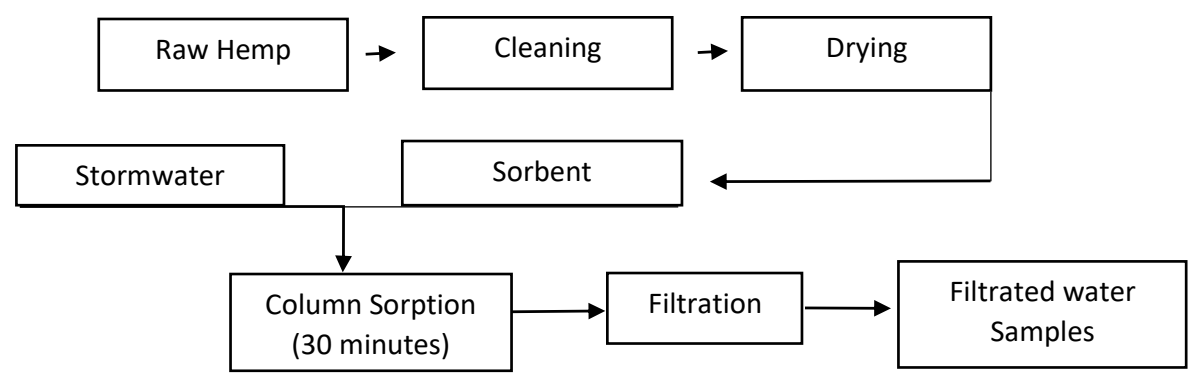

Figure 2. Column test steps of Row Hemp to obtain filtrated water

\section{Analytical methods}

Finally the residence electrical conductivity in every sample was measured by conductivity meter $315 \mathrm{i}$ (made in Germany). The $\mathrm{pH}$ was detected by a $\mathrm{pH}$ Meter 330i (made in Germany). The colour was determined by Spectrophotometer NOVA 60 (made in Germany) with $436 \mathrm{~nm}$ wavelength range and the residual turbidity with wavelength range of $550 \mathrm{~nm}$. The phosphorus concentration was measured by Spectrophotometer Genesys 10 VIS (made in USA) (Carranzo, 2012).

\section{Results and discussion}

In this section the results of using row Hemp and procedured Hemp as sorbent in column test and A. Calamus in jar test to treat water pollution and increase water quality are presented and discussed. 


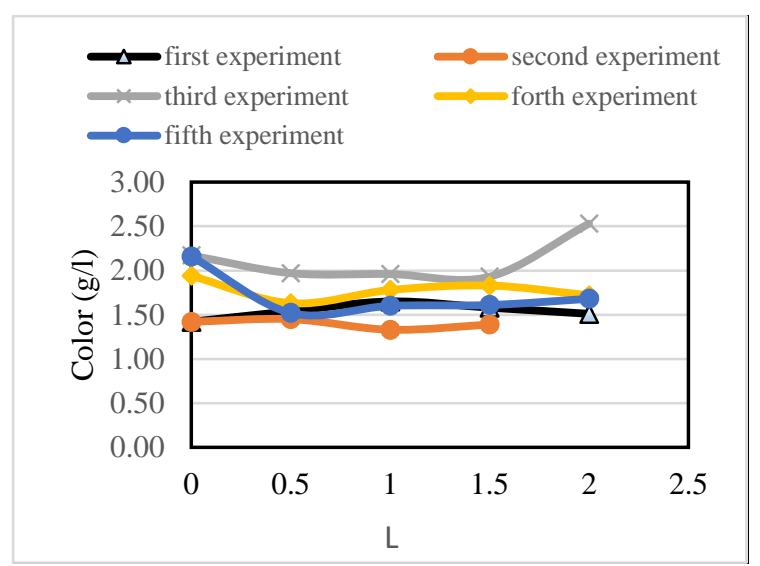

a)

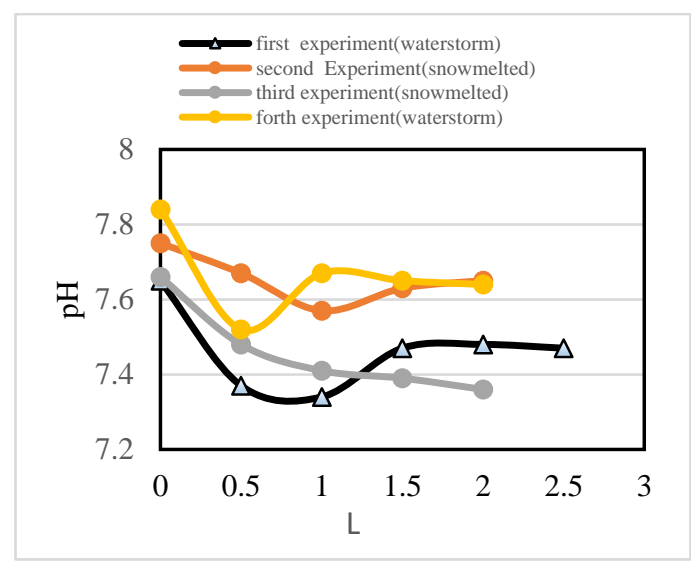

b)

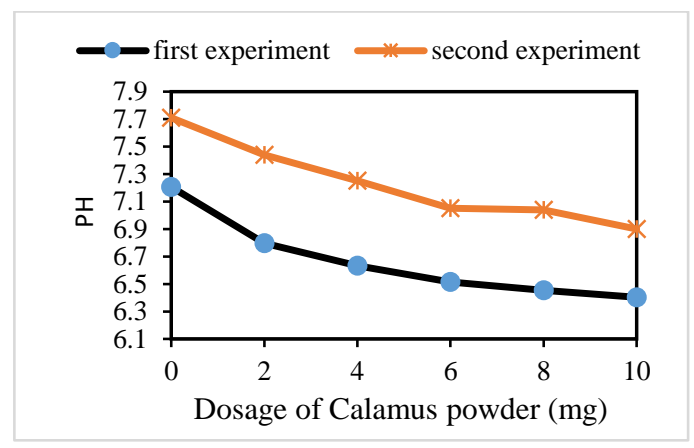

c)

Figure 3. Effect of row Hemp, procedured Hemp and A. Calamus on $\mathrm{pH}$

Results of using Row Hemp (Figure 3a) and procedured Hemp (Figure 3b) as sorbent indicated the same results with Acorus Calamus and Linseed. They have high efficiency to decrease $\mathrm{pH}$ of water that it can be related to the structure and nature of sorbents. Figure $3 \mathrm{c}$ confirm when Acorus Calamus is used as a sorbent, increasing the dosage of the sorbent, the $\mathrm{pH}$ of stormwater decrease to the minimum (6.4) (McDermott \& Strait, 2017). This occurrence can be related to the nature of the sorbent and it would be efficient sorbent to stabilize water $\mathrm{pH}$.

\section{Effect of row Hemp and procedured Hemp on conductivity}

In order to see the effect of row Hemp as a sorbent on conductivity in different volume of stormwater, the Conductivity measurements were taken. It is indicated that by increasing dosage of stormwater (from $0.5 \mathrm{~L}$ to $2 \mathrm{~L}$ ) at first the conductivity increased (in $0.5 \mathrm{~L}$ volume of stormwater) and after that it reduced and stabilized. It should be underscored that at first the dosage of row Hemp for reducing Conductivity from water storm is high because by increasing volume of stormwater the Conductivity reduced and stabilized.

Settling stormwater in row hemp sorbent indicated sudden increase in conductivity because of high dosage of row Hemp that by increasing dosage of stormwater and reducing concentration, it reduced and stabilized (Figure 4a). Effect of procedured Hemp on conductivity showed opposite results with row Hemp sorbent and at first the conductivity decreased dramatically in $0.5 \mathrm{~L}$ of stormwater and by increasing the stormwater it increased and stabilized (Figure $4 b)$.

\section{Effect of natural sorbents on Turbidity}

Reducing Turbidity from stormwater is very important to enhance the quality of water (Baptista et al., 2015). Figure 5 shows effect of natural sorbents on reducing turbidity from stormwater. According to the results presented in figure sorbents they have high efficiency to reduce stormwater turbidity.

According to the results the highest volume of reducing turbidity from water storm is occurred in $0.5 \mathrm{~mL}$ and after that it stabilized until passing its capacity to reduce turbidity. 


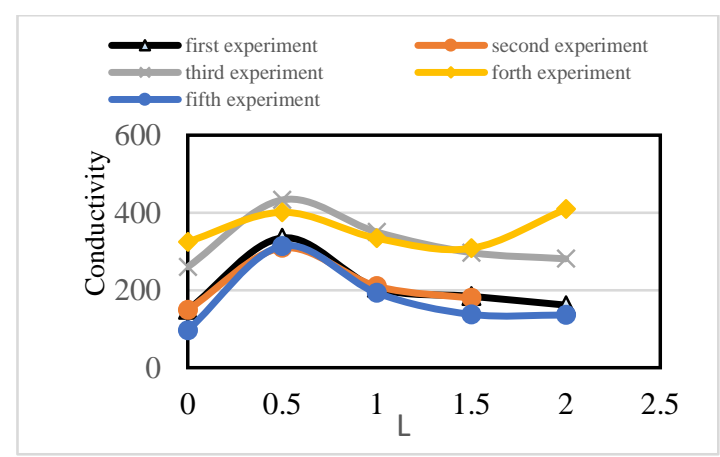

a)

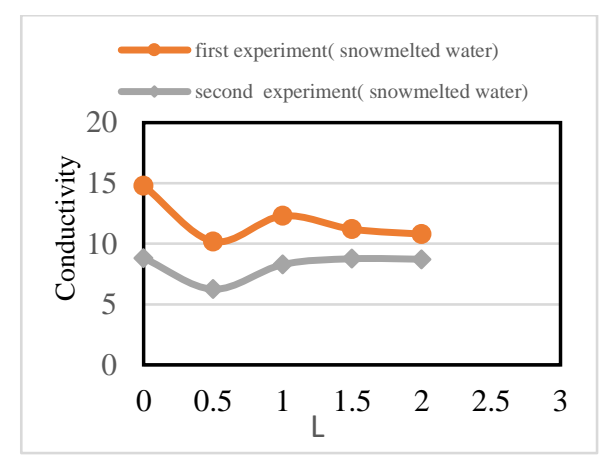

b)

Figure 4. Effect of row Hemp sorbent on conductivity

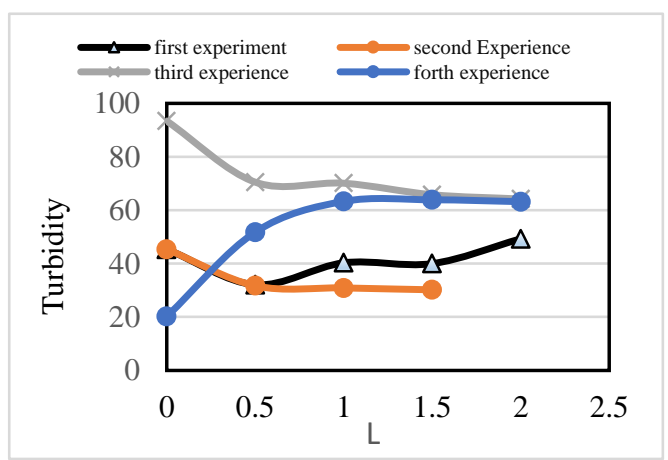

a)

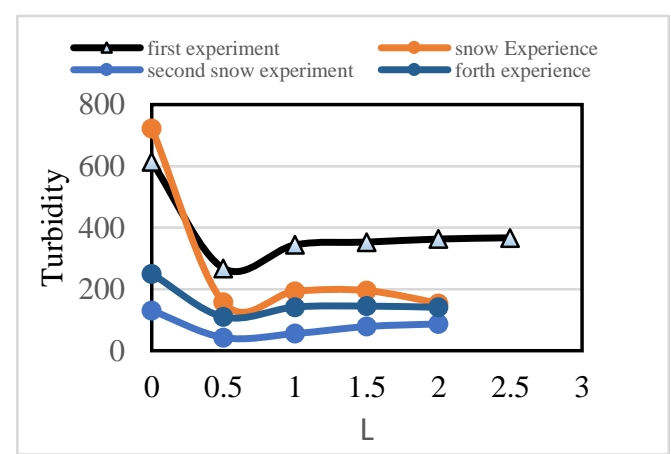

b)

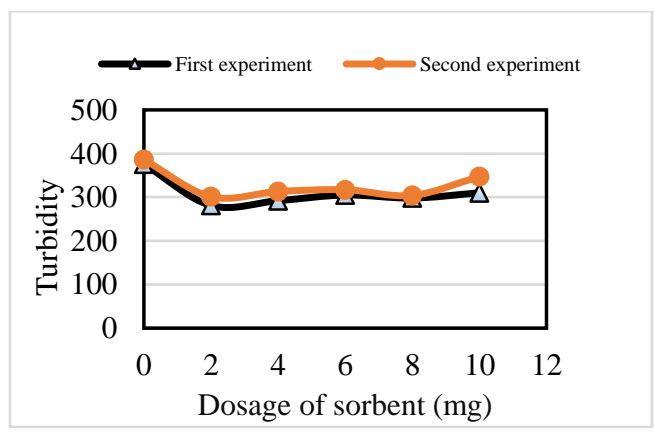

c)

Figure 5. Effect of row Hemp (a), procedured Hemp (b) and linseed (c) on turbidity

In Figure 6 the results of turbidity are expressed in percentage point of turbidity removal, using the following formula (Kamel et al., 2018; Rak \& Ismail, 2012):

$$
\text { Turbidity removal }(\%)=\frac{(\text { initial turbidity }- \text { residual turbidity }) * 100 \%}{\text { Initial turbidity }}
$$

At first because of higher concentration of sorbents, more solution particles are extracted from bio-sorbents that solve in solvent, and removal efficiency is less than other steps (Hu et al., 2013). When the water storm concentration increase the turbidity removal increase and it will continue to fulfil the capacity of sorbent (Gaouar \& Benguella, 2016; Mangale et al., 2012; Mehari et al., 2014; Thomson et al., 2003; Vieira et al., 2010). The turbidity may have different concentrations in different water resources, and different turbidity concentrations may have an effect on sorption (Vijayaraghavan et al., 2011). It is noticeable that the efficiency of turbidity removal by a natural sorbent is significantly influenced by the characteristics and the origin of the sorbent (Ramavandi, 2014). 


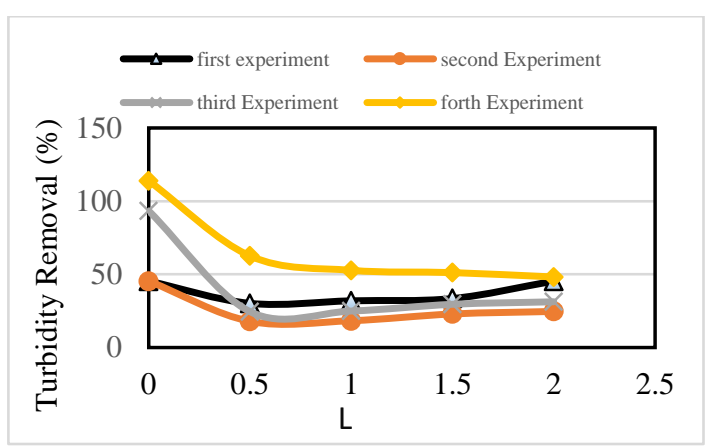

a)

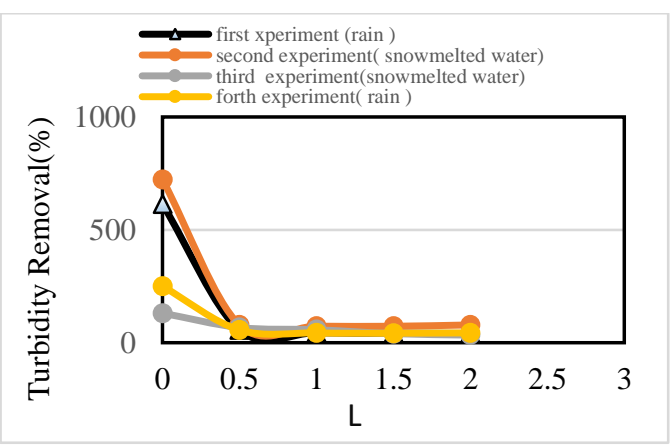

b)

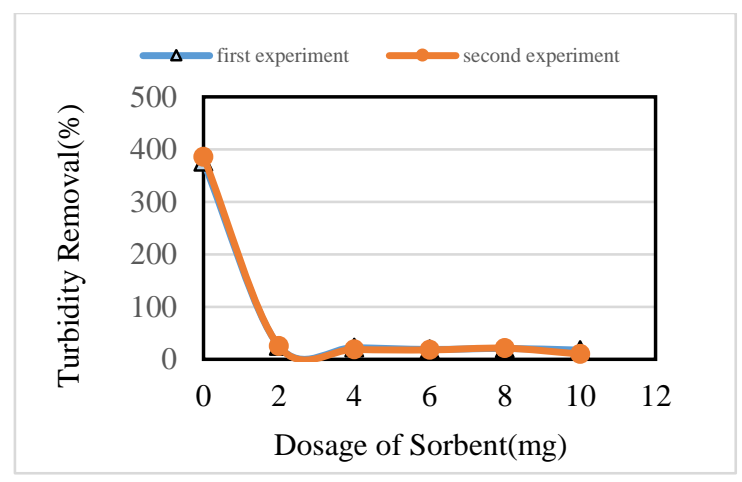

c)

Figure 6. Effect of row Hemp (a), procedured Hemp (b) and linseed (c) on turbidity removal.

According to the results it is obtained that all sorbents have high efficiency to remove turbidity $(76.4 \%, 56.3 \%$ and $25 \%)$

\section{Effect of natural sorbents on color}

Colour removal from water is important to ensure contaminants are filtered out and the water is appealing for different purposes (Ernest et al., 2017). Figure 7 shows effect of natural sorbents on reducing colour from stormwater. According to the results presented in Figure 7, row Hemp and Hemp procedured have high efficiency to reduce stormwater colour.

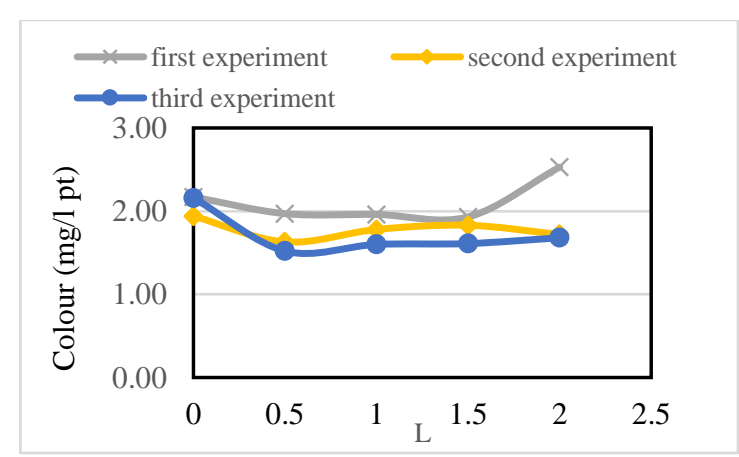

a)

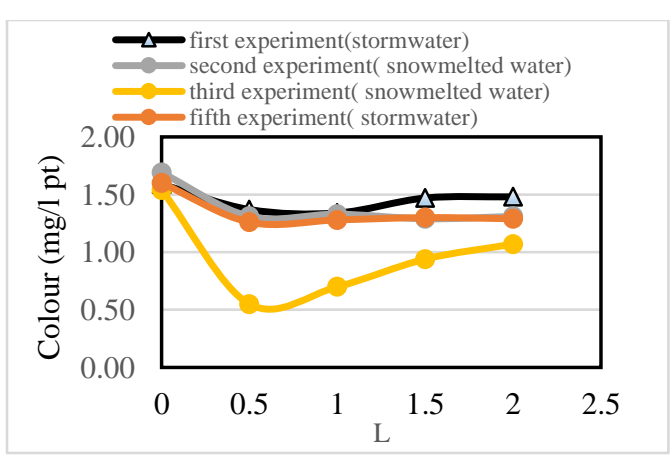

b)

Figure 7. Effect of row Hemp (a), procedured Hemp (b) on color removal. According to the results it is obtained that sorbents have high efficiency to remove color

It is obtained by using row Hemp (Figure 7a) and procedure Hemp (Figure 7b) the colour of stormwater at first step dramatically reduced and after that it stabilized and continued until the sorbent loose its capacity to remove colour.

\section{Conclusions}

The purpose of this study was to investigate the effectiveness of natural sorbents to treat stormwater. In order to confirm sorbent efficiency, different stormwater were collected and experimented using A. Calamus, row Hemp and procedure 
Hemp sorbents showed the same results on $\mathrm{pH}$ and reduced $\mathrm{pH}$ of stormwater. Use of Acorus Calamus powder in detail reduce $\mathrm{pH}$ of stormwater from 7.2 to 6.4 and 7.7 to 6.9. Respectively using row Hemp, Linseeds and procedured Hemp for treating Turbidity from stormwater showed interesting results. It resulted in order $62 \%, 25.2 \%$ and $78.2 \%$ efficiency to remove turbidity. Settling stormwater in row hemp sorbent indicated sudden increase in conductivity because of high dosage of row Hemp that by increasing dosage of stormwater and reducing concentration, it reduced and stabilized. In other side Effect of procedured Hemp on conductivity showed opposite results with row Hemp sorbent and at first the conductivity decreased dramatically in $0.5 \mathrm{~L}$ of stormwater and by increasing the stormwater it increased and stabilized.

Indeed using row Hemp and procedured Hemp as sorbent to treat colour showed decrease in results at lowest concentration of stormwater that by increasing stormwater dosage the colour increased and stabilized. It is to highlight that procedure Hemp has high efficiency to treat water and reducing $\mathrm{pH}$, colour, Turbidity and conductivity.

\section{Acknowledgements}

Visit to VGTU according to ERSMUS exchange programme and express the gratitude to the possibly of my research work.

\section{References}

Abidin, Z. Z., Shamsudin, N. S. M., Madehi, N., \& Sobri, S. (2013). Optimisation of a method to extract the active coagulant agent from Jatropha curcas seeds for use in turbidity removal. Industrial Crops and Products, 41, 319-323. https://doi.org/10.1016/j.indcrop.2012.05.003

Adesina, O. A., Abdulkareem, F., Yusuff, A. S., Lala, M., \& Okewale, A. (2019). Response surface methodology approach to optimization of process parameter for coagulation process of surface water using Moringa oleifera seed. South African Journal of Chemical Engineering, 28, 46-51. https://doi.org/10.1016/j.sajce.2019.02.002

Ata, A., Nalcaci, O. O., \& Ovez, B. (2012). Macro algae Gracilaria verrucosa as a biosorbent: A study of sorption mechanisms. Algal Research, 1(2), 194-204. https://doi.org/10.1016/j.algal.2012.07.001

Baptista, A. T. A., Coldebella, P. F., Cardines, P. H. F., Gomes, R. G., Vieira, M. F., Bergamasco, R., \& Vieira, A. M. S. (2015). Coagulation-flocculation process with ultrafiltered saline extract of Moringa oleifera for the treatment of surface water. Chemical Engineering Journal, 276, 166-173. https://doi.org/10.1016/j.cej.2015.04.045

Carranzo, I. V. (2012). Standard methods for examination of water and wastewater. Paper presented at the Anales De Hidrología Médica.

Choy, S. Y., Prasad, K. M. N., Wu, T. Y., Raghunandan, M. E., \& Ramanan, R. N. (2014). Utilization of plant-based natural coagulants as future alternatives towards sustainable water clarification. Journal of Environmental Sciences, 26(11), 2178-2189. https://doi.org/10.1016/j.jes.2014.09.024

Ernest, E., Onyeka, O., David, N., \& Blessing, O. (2017). Effects of pH, dosage, temperature and mixing speed on the efficiency of water melon seed in removing the turbidity and colour of Atabong River, Awka-Ibom State, Nigeria. International Journal of Advanced Engineering, Management and Science, 3(5). https://doi.org/10.24001/ijaems.3.5.4

$\mathrm{Fu}, \mathrm{X}$. (2015). Phosphorus removal from wastewater by five aquatic plants. Paper presented at the $3^{\text {rd }}$ International Conference on Advances in Energy and Environmental Science. https://doi.org/10.2991/icaees-15.2015.186

Gaouar, M. Y., \& Benguella, B. (2016). Efficient and eco-friendly adsorption using low-cost natural sorbents in waste water treatment. Indian Journal of Chemical Technology (IJCT), 23(3), 204-209.

Hsieh, C.-h., Davis, A. P., \& Needelman, B. A. (2007). Bioretention column studies of phosphorus removal from urban stormwater runoff. Water Environment Research, 79(2), 177-184. https://doi.org/10.2175/106143006X111745

Hu, C.-Y., Lo, S.-L., Chang, C.-L., Chen, F.-L., Wu, Y.-D., \& Ma, J.-1. (2013). Treatment of highly turbid water using chitosan and aluminum salts. Separation and Purification Technology, 104, 322-326. https://doi.org/10.1016/j.seppur.2012.11.016

Iqbal, A., Hussain, G., Haydar, S., \& Zahara, N. (2019). Use of new local plant-based coagulants for turbid water treatment. International Journal of Environmental Science and Technology, 16(10), 6167-6174. https://doi.org/10.1016/j.seppur.2012.11.016

Javid, A. H., Malakootian, M., \& Mehdipour, M. (2015). Investigation of ozone and coagulant material's (aluminum sulfate, ferric chloride, poly aluminum chloride and lime) efficiency in "Kerman Kork" industry wastewater treatment. Environmental Health Engineering and Management Journal, 2(1), 1-6.

Jones, A. N., \& Bridgeman, J. (2019). A fluorescence-based assessment of the fate of organic matter in water treated using crude/purified Hibiscus seeds as coagulant in drinking water treatment. Science of the Total Environment, 646, 1-10. https://doi.org/10.1016/j.scitotenv.2018.07.266

Kainth, G. S. (2015). Removal of turbidity from water using low cost adsorbent. Rourkela, National Inistitude of Technology.

Kamel, S., Zaki, Z., \& Kassim, J. (2018). The effectiveness of psophocarpus tetragonolobus's seed as turbidity removal. International Journal of Engineering and Technology, 7(3.11), 144-146. https://doi.org/10.14419/ijet.v7i3.11.15949

Lopez, F. C., \& Postila, H. (2018). Evaluation of effectivity of peat as sorbent material for mining water purification in pilot scale system. Finland, University of Oulu. 
Mahmood, N. C., \& Zaki, Z. M. (2019). The effectiveness of raw and dried Artocarpus Heterophyllus (Jackfruit) seed as natural coagulant in water treatment. Paper presented at the Materials Science and Engineering Conference. https://doi.org/10.1088/1757-899X/601/1/012010

Mangale, S., Chonde, S., Jadhav, A., \& Raut, P. (2012). Study of Moringa oleifera (drumstick) seed as natural absorbent and antimicrobial agent for river water treatment. Journal of Natural Product and Plant Resourse, 2(1), 89-100.

McDermott, M. D., \& Strait, W. D. (2017). Water quality: improving water quality utilizing Hemp. Journal of Agriculture and Environmental Sciences, 6(2), 13-15. https://doi.org/10.15640/jaes.v6n2a2

Mehari, B. B., Mayabi, A. O., \& Hadgu, L. T. (2014). Preliminary assessment of low cost local sorbent materials for water defluoridation in Keren, Eritrea. International Journal of Sciences: Basic and Applied Research (IJSBAR), 18(1).

Okuda, T., \& Ali, E. N. (2019). Application of Moringa oleifera plant in water treatment. In X. T. Bui, C. Chiemchaisri, T. Fujioka, \& S. Varjani (Eds.), Water and wastewater treatment technologies (pp. 63-72). Springer. https://doi.org/10.1007/978-981-13-3259-3_4

Pearson, B. J., Chen, J., \& Beeson, R. C. (2018). Evaluation of stormwater surface runoff and road debris as sources of water pollution. Water, Air and Soil Pollution, 229(6), 194. https://doi.org/10.1007/s11270-018-3793-2

Rak, A. E., \& Ismail, A. A. M. (2012). Cassia alata as a potential coagulant in water treatment. Research Journal of Recent Sciences, l(2), 28-33.

Ramavandi, B. (2014). Treatment of water turbidity and bacteria by using a coagulant extracted from Plantago ovata. Water Resources and Industry, 6, 36-50. https://doi.org/10.1016/j.wri.2014.07.001

Sahu, R. L., Dash, R. R., Pradhan, P. K., \& Das, P. (2019). Effect of hydrogeological factors on removal of turbidity during river bank filtration: Laboratory and field studies. Groundwater for Sustainable Development, 9, 100229. https://doi.org/10.1016/j.gsd.2019.100229

Shan, T. C., Al Matar, M., Makky, E. A., \& Ali, E. N. (2017). The use of Moringa oleifera seed as a natural coagulant for wastewater treatment and heavy metals removal. Applied Water Science, 7(3), 1369-1376. https://doi.org/10.1007/s13201-016-0499-8

Thomson, B. M., Smith, C. L., Busch, R. D., Siegel, M. D., \& Baldwin, C. (2003). Removal of metals and radionuclides using apatite and other natural sorbents. Journal of Environmental Engineering, 129(6), 492-499. https://doi.org/10.1061/(ASCE)0733-9372(2003)129:6(492)

Vieira, A. M. S., Vieira, M. F., Silva, G. F., Araújo, Á. A., Fagundes-Klen, M. R., Veit, M. T., \& Bergamasco, R. (2010). Use of Moringa oleifera seed as a natural adsorbent for wastewater treatment. Water, Air, and Soil Pollution, 206(1-4), $273-281$. https://doi.org/10.1007/s11270-009-0104-y

Vijayaraghavan, G., Sivakumar, T., \& Kumar, A. V. (2011). Application of plant based coagulants for waste water treatment. International Journal of Advanced Engineering Research and Studies, 1(1), 88-92.

Yu, M., Hong, G., Xu, H., Zhu, G., Zhu, M., \& Quan, Q. (2019). Effects of cyanobacterial blooms in eutrophic lakes on water quality of connected rivers. Huan jing ke xue= Huanjing kexue, 40(2), 603-613.

Zaidi, N. S. (2019). Potential of fruit peels in becoming natural coagulant for water treatment. International Journal of Integrated Engineering, 11(1). https://doi.org/10.30880/ijie.2019.11.01.017 